\title{
DISCINESIAS DAS VIAS BILIARES
}

\author{
DR. CESAR GIRARD JACOB
}

Antes de iniciarmos o estudo das discinèsias, propriamente ditas, convêm recapitularmos, sucintamente, alguns dados anatomicos para melhor compreensão do assunto.

Nas vias biliares extra-hepaticas ha duas formações musculares principaes, de cujo funcionamento pẻrfeito depende o escoamento de bile até o duodeno: o esfincter do colo da vesicula e o esfincter de OpDI.

Este ultimo, particularmente interessante para o nosso caso, é formado por dois anéis : um proximal e outro distal. $\bigcirc$ proximal, exclusivo do colédoco, é constituido por fibras musculares longitudinaes e obliquas; a porção superior deste anél se acha unicla à camada muscular do duodeno, e a inferior, á muscularis-mucosa do mesmo orgão.

O' anél distal, comum ao colédoco e ao canal de Wirsung, abraça á maneira de um oito os dois condutos, e é menos robusto que o primeiro. Segundo Westratal o anél superior ou proximal - tambem denominado antro do esfincter de ODDI - seria a zona vagal do esfincter; o inferior ou distal seria territorio do simpatico.

Além do esfincter de ODDI e o do colo da vesicula poderiamos considerar um terceiro anél muscular, ao longo do hepatico, cujo mecanismo contrátil, verificado por Mirizzi em estudos de colangiografia operatoria, o elevaria á condição de esfincter. Devemos lembrar ainda, para ezáta compreensão da função excretoria, que a luz do cistico é franjada pelas valvulas de HEISTER; estas valvulas dispõem-se em espiral afim de impedir o achatamento ou distenção do conduto nas variações de pressão da vesicula.

\section{FISIOLOGIA DA EXCREÇÃO BILIAR}

O escoamento de bile no duodeno é regulado, principalmente, pelo esfincter de ODDI. O papel atribuido por certos autores á motilidade e ao tonus da musculatura duodenal, no contrôle do fluxo biliar, parece relegado a segundo plano, sobretudo depois de certas verificações experimentaes, entre as quaes avultam as de ScHwengler e Boyden. Para estes autôres o esfincter "é tão bem desenvolvido 
e tão estrategicamente colocado que é capaz de deter a onda biliar no duodeno, independentemente da musculatura intestinal"

O mecanismo de abertura ou oclusão está na dependencia das diversas fases digestivas. Segundo Mac Master e Elman, ao terminar a digestão observa-se um aumento no tonus do esfincter, e uma hipertensão no hepato-coledoco; no momento em que a pressão atinge 70 mms. de bile esta começa a escoar na vesicula, "onde é deshidratada e armazenada tão rapidamente de modo a não permitir que a pressão nos condutos exceda de 100 a 120 mms".

$\mathrm{Na}$ fase digestiva a pressão no interior dos condutos alcança estes limites, observando-se então o relaxamento esfincteriano, e consequente escoamento de bile para o intestino.

Os numeros relativos á pressão intra-canalicular variam conforme se toma bile ou agua como ponto de referencia; é assim que para IMANAGA a pressão normal interna do colédoco oscila em torno de 80 a 120 mms. de agua, e aquela capaz de vencer a resistencia ido ODDi, é calculaḍa em $190 \mathrm{mms}$.

Os valores atribuidos por Koster são mais elevados, chegando ele a admitir cifras correspondentes a 200, 300 e mesmo até $400 \mathrm{mms}$. de agua. A pressão de $400 \mathrm{mms}$. seria aliás superior á capacidade de resistencia do ODDI: Achamos inteŗessante citar estes numeros porque deles se infére que a maior ou menor secreção biliar desempenha um papel salientè na evacuação coledociana.

Na repleção da vesicula entram em cêna os seguintes fatores: contração do esfincter de OD̉i, aumento da pressão biliar no colédoco, abertura do esfincter do colo e consecutivo deslocamento das valvulas de Heister, dé modò que o enchimento vesicular, nos intervalos da digestão, se processa á custa do antagonismo reflexo das duas formações esfincterianas e da hipertensão do colédoco.

Entretanto não são exclusivamente as variações de pressão que controlam, harmonicamente, estas aberturas e fechamentos de comportas; para esse trabalho sinérgico concorrem, e de forma capital, fatôres neura-humoraes. Como agente hormonal merece citada a Colecistoquinina, descoberta em 1927 por Ivy e OldBerg, atravéz a circulação cruzada em cães.

E' uma substancia secretada pela mucosa do duodeno em contáto com acido clorhidrico, gorduras e, provavelmente, outros materiaes alimentares. Já existe isolada, em estado de pureza, não contendo histamina nem secretina. Goza da propriedade de aumentar o tonus do duodeno e diminuir o do esfincter de Oddi.

A respeito da contribuição neurc-vegetativa na fisiologia da excreção biliar, falaremos dentro em pouco, á proposito das experiencias fundamentaes de WESTPHAL. 


\section{DISCINESIA DAS VIAS BILIARES}

Adotamos esta expressão não só pelo fáto de ser a mais frequentemente esposada pelos autoręs como tambem pela vantagem que apresenta de focalizar, numa visão de conjunto, toda a complexidade da entedidade morbida.

Outras designações ha, todas elas unilateraes, objetivando apenas uma face do problema; assim é que para Schmieden é uma COLOPATÍA ESPASTICA: Best e HICKen dão-lhe o nome de DISSENERGIA DO COLÉDOCÓ; são ainda encontradiças expressões como PAPILITE, ESFINCTERITE, RESISTENCIA DA PAPILA DE VATER, COLEDOCO-ODDITE ESCLERO RETRATIL, ODDITES, e outras talvez que no momento nos escapam.

Esta abundancia de epítetos é propria da relativa obscuridade em que nos encontramos no que diz respeito á etio-patogenia da afecção. Neste dominio cabe o paradoxo de Miguel Couto, segundo o qual em medicina fartura é sinonimo de penuria.

Discinésia biliar compreende, segundo Lipschutz, os disturbios da motilidade e tonicidade da vesicula e canaes biliares; disturbios funcionaes, que se contrapõem ás afecções organicas das referidas vias.

LEPEHNE dá ás discinésias a acepção de perturbações funcionaes puras do mecanismo da vesicula e dos canaes biliares, e os incomodos por elas causados.

Von Bergman tambem admite este caráter funcional puro da afecção e a possibilidade de, secundariamente, alcançar um substráto anatomico. Todavia, as discinésias genuinas, como acentúa o proprio VoN BERGMAN, são raras; frequentemente exteriorizam fenomenos que surgem num orgão já em certo estado de irritação, como por exemplo um processo inflamatorio.

Timbramos em frizar aqui o pensamento do Prof. VAN DER ReIs, segundo o qual seria duvidosa a existencia de discinésias puras, isto é, exclusivamente funcionaes; elas seriam condicionadas por fatôres organicos que nem sempre estariam ao alcance dos nossos atuaes meios de pesquiza.

E' um capitulo recente da Patologia porquanto só em 1920 é que realmente se tornou objéto de atençãoj Apezar de Aschoff e BACHMEISTER observarem, á mesa operatoria, em 1909, casos tipicos de colica hepatica com ausencia de calculos ou qualquer outro processo organico, e de usarem, pela primeira vez, a expressão - Vesicula estatica -, apezar dessas verificações, dez anos se passaram, até vir á luz a monografia de SCHMIEDEN - Estase da vesicula biliar, Neste trabalho o autôr estuda casos identicos aos citados por Ascroff, pondo em relevo o fato de em todos eles a vesicula encontrar-se distendida, e atribuindo a esta distenção as colicas de que se queixavam os pacientes. 
Entretanto, quem primeiro concebeu a ideia de um disturbio funcional, na genese dessas estases, foi BERG, ao notar, em certos casos, hipertrofia consideravel das fibras musculares que circundam a empôla de Vater.

Outros observadores constataram fatos identicos e as atenções, naturalmente, voltaram-se para o esfincter descrito por ODDI nos animaes, em 1887, e no homem por Hendrickson em 1900 . Sugeriu-se então, pela primeira vez, a hipotese de uma possivel relação causal entre espasmo dó esfincter e colicas vesiculares, identicas áquelas determinadas por calculos.

Em 1923 Westphal, a instancias de Von Bergman, que já. havia estabelecido o conceito de discinésias relativamente ás funções. do colon, estudou clinica e experimentalmente as funções neuro-musculares das vias biliares.

Westrhal, em experiencias magistraes, substituiu as noções vagas que então imperavam, por uma concepção clara dos disturbios motores vesiculares e coledocianos; realmente, em 1931, as discinésias ascendem á categoria de entidade definida, no trabalho por ele publicado em colaboração com Gleichman e Mann.

Foi no decurso de suas experiencias que Westphal concluiu pela dupla constituição, anatomica e funcional, do esfincter de OdDI, como vimos ha pouco. Eis como Lipschutz nol-as descreve: "Empregando uma corrente faradica, de pequena intensidade, ele estimulava a Vago, logo abaixo do diafragma, e observava que a vesicula se contraia, relaxava-se ao mesmo tempo a papila instalando-se, simultaneamente, movimentos peristalticos em direção á porção antral do esfincter. Deduziu, em face destas verificações, que a resposta aos estimulos normaes da digestão, seria identica a esta.

Usando corrente mais forte, notou um aumento acentuado no tonus da musculatura vesicular e uma maior atividade peristaltica em direção á empôla de VATER. Esta condição seria, indubitavelmente, a causa de uma evacuação mais rapida da vesicula que nos processos normaes da digestão, e tal hipermotilidade, ocorrendo no homem, realizaria o quadro da discinésia hipercinetica por hipermotilidade.

Uma corrente ainda mais forte determinava contração volenta da vesicula e espasmo do esfincter de ODDI. Tal espasmo, concluiu, deve ser muito doloroso porquanto se associa a uma distenção: designou então este estado com a expressão: discinésia hipertonica"

"Verificou Westphal, por outro lado, que estimulos faradicos do simpatico invertiam esses fenomenos, processando-se, nesse caso, relaxamento da vesicula e da porção antral do esfincter, e contração da zona distal deste ultimo. Deduziu tambem, tanto quanto tho permitiam os dados experimentaes, que esta excitação simpatica não deve causar dôr intensa, responsabilisando-a pela variedade atonica das discinésias" 

vesicula.

Ive sugere ainda a possibilidade de espasmos ao nivel do colo da

Em resumo, é esta a classificação de WestphaL:

$$
\text { DISCINESIAS }\left\{\begin{array}{l}
\text { HIPERCINÉTICA }\left\{\begin{array}{r}
\text { B) Hipertonicidade: a vesicula contráe-se } \\
\text { com o esfincter em epasmo; dis- } \\
\text { tenção espastica e dôr, isto é, } \\
\text { colica. }
\end{array}\right. \\
\text { AṬonica } \\
\left\{\begin{array}{l}
\text { Atonia ou relaxamento da vesicula com } \\
\text { espasmo do esfincter; a resultante é uma } \\
\text { distenção vesicular atonica com consequente } \\
\text { mal estar caracteristico. }
\end{array}\right.
\end{array}\right.
$$

Pablo Mirizzi, cuja autoridade neste dominio é inconteste, propõe outra sistematica, baseado em magistraes estudos colangiogra-. ficos. Para todos os casos de obstrução do esfincter ele reserva a denominação de Odites; as oddites, por sua vez, compreendem duas modalidades: distonicas e estenoticas.

Nas distonias ha desordem funcional caracterisada por fechamento incompleto do esfincter; nestas circunstancias ha espasmo localisado; apenas, ao nivel da porção simpatica ou disţal, mantendo-se aberto o anél antral ou vagal. Nas distonias haverá refluxo para o conduto de Wirsung e dahi se compreende a importancia que esta modalidade de discinésia póde assumir na genese das pancreatites.

As oddites estenoticas compreendem todos os casos de estenose, organicos ou funcionaes; do esfincter.

Mirizzi compara as distonias ao distireoidismo dos dualistas; emquanto que as oddites estenoticas encontrariam paralélo no hipertireoidismo. No primeiro caso observa-se uma função dissociada, e no segundo, exaltada.

Entretanto a classificação de Mrrizzi se ressente de um vicio que, ao nosso vêr, a comprométe; efetivamente, a desinencia "ite", do termo oddite, especificadora que é de estados inflamatorios, póde suscitar confusão. Por esta e outras razões, entre as quaes a de ser menos didatica, preferimos a de WestPHaL.

\section{ETIOLOGIA}

Ha uma tendencia geral em responsabilizar-se as distomias neuro-vegetativas como causas mais frequentes das sindromes discinéticas. Pode haver predominancia dos disturbios simpaticos, ou para-simpaticos, sendo porêm, clinicamente dificil, muitas vezes, uma delimitação nitida entre os dois estados. 
$\mathrm{Ha}$ fatôres constitucionaes que parecem predispôr á realização de um ou outro tipo de discinésia. LIPSCHUTz encontrou casos com espasmos sumultaneos de outros orgãos: duodeno irritavel, colon irritavel, piloro-espasmo.

O mesmo autôr assinála a frequencia com que se encontram associados os fenomenos alergicos e os disturbios funcionaes de que nos ocupamos, afirmando mesmo que grande numero das pseudo-afecções das vias biliares associadas á alergia alimentar, descritas por muitos autôres, nada mais são que desordens funcionaes puras.

Cabe aqui menção ao fato de certas fases da vida genital da mulher predispôrem aos surtos discinéticos. Segundo uma "enquete" de EPPINGER, dentre dezoito senhoras gravidas apenas seis apresentavam evacuação normal da vesicula. Para WESTPHAL este retardamento da excreção na gestante seria um fatôr etiologico importante de colelitiase, e estaria ligado á vagotonia, comum nesses estados da vida feminina.

Entre os estados organicos responsaveis por espasmos das vias biliares, merecem citadas as afecções inflamatorias e calculosas da vesicula. Surge aqui a questão referente á etio-patogenia da litiase, sendo licito emitir duas eventualidades na causalidade primaria do processo: ou a inflamação tem prioridade de causa, sobrevindo posteriormente a estase, a precipitação calculosa e, subsequentemente, os. espasmos, ou estes assumem a dianteira na sequencia -morbida.

- A este proposito convem lembrar alguns fátos bem estabelecidos. $E$ ' sabido que nos individuos que sofrem extirpação da vesicula observam-se, com frequencia, duas fases no comportamento do esfincter de ODDI: num primeiro tempo ele se torna incontinente, relaxado, sobrevindo, posteriormente, hipertrofia de suas fibras.

Já em 1925 Dé VALLE relatava observações relativas a pacientes que, apezar de colecistectomizados, continuavam prezas de colicas hepaticas identicas ás do periodo pré-operatorio. Em todos eles havia estenose da papila de VATER. O obstaculo, á principio puramente funcional, é condicionado, posteriormente, por um substráto anatomico: hipertrofia do esfincter com estenose da empôla.

Aliás, a ocorrencia de hipertrofia esfincteriana nos animaes colecistectomizados, é um fato de verificação experimental. Petrer e MANN demonstraram que a pressão no colédoco do cão aumenta depois da extirpação da vesicula, e atribuem este fato a um espasmo do ODDI.

Identicas experiencias levaram a efeito MAC MASTER e Elman, constatando uma hipertensão de $320 \mathrm{mms}$., quando nas condições normaes a pressão não chega a mais de $120 \mathrm{mms}$., limite maxima em face do qual o esfincter se abre para dar vasão á bile.

BeSt e HiCKen em estudos colanfiograficos operatorios observaram acentuado espasmo do esfincter resultando em obstrução temporaria e bloqueio do fluxo biliar para o duodeno. 
WALTERS e colaboradores procederam a estudos em pacientes colecistectomizados, com o objetivo de determinar a influencia do esfincter de ODDI sobre a pressão do coledoco. Para isto serviram-se de um tubo em $\mathrm{T}$, introduzido neste ultimo, e ligado a um manometro; verificaram então um aumento de pressão toda a vez que sobrevinha uma crise dolorosa. Injetando substancia opaca pelo tubo obtiveram comprovação radiologica do espasmo pois o contraste, ao invéz de alcançar o duodeno, refluia para as vias biliares intra-hepaticas.

Estes achados experimentaes e as observações in anima nobile constituem advertencia para os intervencionistas á outrance: a colecistectomia nem sempre é destituida de sequelas desagradaveis.

Os estados inflamatorios do duodeno tambem podem tornar-se responsaveis pelos espasmos do ODDI, e neste particular são muito interessantes as observações de Paunesco e Podeano.

E' logico supor-se que muitas afecções organicas, mesmo não adstritas ao territorio digestivo, sejam capazes de provocar disturbios das vias extra-hepaticas por intermedio de conexões nervosas, porquanto não se deve perder de vista o fáto de que o sêr humano é um todo organico e não um agregado de compartimentos estanques.

\section{SINTOMATOLOGIA}

$\mathrm{Na}$ discinésia atonica o sintoma subjetivo mais constante é a sensação de peso no hipocondrio direito. Segundo CHIRAY ha sempre anorexia rebelde, que se opõe a uma alimentação racional, fazendo algumas vezes pensar em anorexia mental.

Além da lingua saburrósa e nauseas, nada caracteristicas, podem sobrevir vomitos biliosos mais ou menos abundantes, em forma de crises, constituindo as crises biliosas de Chiray e Gerolami.

Entre os sintomas distantes mais frequentes, segundo TrIbovLET, merece citada a enxaqueca biliar, caracterizada por dores hemicranicas, mais ou menos violentas, acompanhadas por um cortejo de fenomenos vaso-motôres ou nervosos, taes como: vermelhidão do rosto, queimação no couro \abeludo, entumescimento dos olhos.

A ictericia assim como o descoramento das fézes seriàm sintomas excecionaes.

Neste tipo se enquadra o seguinte caso, cúja observação agradeço aó Dr. Paúlo Dias, do serviço á cargo do Dr. Levy Sodré.

"J. P., 26 anos, brasileiro, casado, branco, natural da Baía; escriturario. Em seu passado acusa blenorragia e cancro sifilitico aos 20 anos. Aos 16 impaludismo durante dois anos.

Ha quatro anos começou a sentir anorexia e fraqueza; tomou fortificantes, á consedho medico, e de nada valeram. Fez um Wassermann, e como o resultado fosse fortemente positivo submeteu-se a tratamento esperifico: (914, bismuto e mercurio) o qual se prolongára até o momento desta observação. Com este tratamento o apetite melhorou um pouco; entretanto, as melhoras não foram apreciaveis. 
De dois anos para cá surgiram dôres na metade direita do epigastro, localizadas na vesicula por $1 \mathrm{~m}$ radiologista. Estas dôres, bem localizadas á direita, não são muito intensas, não apresentam irradiação e aliviam-se con o repouso, principalmente em decubito lateral direito; reaparecem ao levantar-se ou quando marcha. Não tem horario: algumas vezes melhoram, doutras peioram com a alimentação; acompanham-se de grande mau humor,. irritabilidade e desanimo. Elas não são de grande duração; aparecem apenas por alguns dias, mais frequentemente algumas horas, ausentando-se durante mezes.

Entretanto, nestas fases de acalmia não deixa de apresentar perturbaçes dispépticas, taes como piróse e plenitude post-prandial, acompanhadas de sensação de aperto pre-cordial; estes sintomas, todavia, são mais intensos por ocasião das crises dolorosas, "quando tudo parece complicar por dentro", segundo suas proprias palavras.

O reaparecimento destas crises pode ser provocado, de modo absolutamente constante, pela ingestão de gemas: meia hora depois a dôr surge. As viagens parecem exercer a mesma influencia. Ha certos alimentos, como abacate e banana, que tomados em excesso tambem determinam o aparecimento ou a exacerbação da dôr.

Refere prisão de ventre, já há quatro anos; este sintóma foi como que o precursor de todos os outros. Passa tres a quatro dias sem defecar; as fézes são escuras parecendo ás vezes pó de café. Não expéle sangue nem muco. Um exame coprologico feito há tempo nada revelou de anormal. Tem emagrecido.

Queixa-se de cefaléia; nega nauseas e vomitos; eructaçõés frequentes, de sabôr azedo, acompanhadas por vezes de regurgitação de liquidos que não queimam a garganta, e que alivia um pouco o seu mal estar.

Ex. objetivo: Ponto vesicular doloroso. Manobra de Muriphy positiva. Ponto de Mac-Bunes indolor. Figado de dimensões normaes. Colons livres.

Uma intubação feita em 3 de Outubro de 1941 colheu 50 cc. de bile vesicular preta, hiperconcentrada portanto; a analise revelou ausencia de elementos. anormais nas tres biles.

Uma colecistografia, em 20 de Junho de 1940, pelo Dr. Moretzsohn DE CAstro, dá o seguinte resultado: "Colecistograma positivo. Vesicula de situação, forma e dimensões normais. Ausencia de sombras calculosas. Prova de BOYDEN: fraca resposta vesicular aos trinta minutos depois da ingestão. das gemas; presença de grande quantidade de bile residual com duas horas após a ingestão. Sinais radiologicos de discinésia vesicular hipotonica por provavel processo de colecistite.

Outra radiografia, de estomago e duodeno, feita pelo Dr. MoretzsoH, em 15 de Setembro de 1941 nada revelou de anormal; constatou-se apenas sensibilidade á palpação nos pantos vesicúlares.

Radiografia dos colons, em 25 , de Setembro de 1940 , revelou transito normal. até o cecum; aspécto irritativo da mucósa do descendente; desaparecimento da. haustração normal e do relevo da mucosa do sigmoide. Sinais radiologicos de sigmoidite mucosa. Neurose intestinal reflexa.

Em Março do corrente ano, um exame funcional do figado, pela prova da santonina, respondeu dentro da normalidade".

Este caso, pela sua sintomatologia, pela ausencia de elementos anormais nas tres biles, pela tomalidade sombria da bile $\mathrm{B}$, e sobretudo, pela fraca resposta vesicular á prova de Boyden deve ser enquadrado na variedade atonica das discinésias. 


\section{DISCINESIAS POR HIPERMOTILIDADE}

As discinésias por hipermotilidade seriam talvez um dos fatôres causaes da diarréa prandial. Esta sindrome, descrita por Linossier, caracteriza-se por abundante evacuação diarréica estreitamente ligada á ingestão de alimentos, como o seu proprio nome o indica.

Eis como ele a descreve: "O doente sente á principio dôr intensa no concavo epigastrico ou ligeiramente á direita, ao nivel da vesicula, algumas vezes com irradiação para o umbigo ou para or tórax". Por vezes é tão viva que se acompanha de palidez, suores frios, mais excepcionalmente de uma sensação de aniquilamento e perda do conhecimento. A dôr epigastrica é, em geral, de curta duração. Depois de alguns segundos ou minutos ela dá lugar a colicas intestinaes, geralmente mais toleraveis, e a uma necessidade de evacuar, por vezes tão imperiosa que, obrigando o paciente a abandonar a mesa, precipitadamente, não lhe dá tempo, em certas ocasiões, de alcançar o gabinete antes de processar-se a debacle.

As féses são constituidas por bile pura ou bile de mistura com dejeções". A' esta situação de angustia e mal estar sucéde um estado eufórico, permitindo ao paciente, muitas vezes, continuar a refeição interrompida.

O ezame coprologico, nas diarréias prandiaes, caracteriza-se, segundo Binet, pelos sinaes de uma evacuação acelerada: indice de fermentação muito acentuado, expresso pela taxa bastante acrescida de acidos organicos, múco abundante e pigmentos biliares. $\mathrm{O}$ volume anormalmente grande de bile, lançado intempestivamente no duodeno, determina hipercinéia e hipersecreção intestinaes, revelados pelo exame funcional.

$\mathrm{Na}$ realidade os sintomas nem sempre obedecem ao paradigma traçado por Linnossier; todavia, dois elementos seriam predominantes na discinésia por hipermotilidade: dôr no hipocondrio direito e diarréia.

O drama é, em geral, secundario a determinados alimentos; ha substancias eletivas no desencadeamento da crise e, a este proposito, convêm lembrar a importancia que dá Von BERGMann aos elementos ricos em gordura nos disturbios discinéticos.

Vem a pelo a seguinte obs̉ervação gentilmente cedida pelo $\mathrm{Dr}$. José Pontes, do serviço á cargo do Dr. Levy Soḍré:

B. de R. - 23 anos - casada - branca - brasileira. Ha dois anos vem sentindo dôr em pontada, no hipocondrio direito, dôr que aparecia irregularmente, durante o dia, mas principalmente depois das refeições. Estas pontadas não eram muito intensas e surgiam mais frequentemente quando ingeria ovos, fritadas, leite, feijão e alimentos gordurosos.

Ha um ano, de madrugada, acordou sentindo perturbações sensoriais e peso no hipocondrio direito; aos poucos este peso foi desaparecendo, ao mesmo tempo em que se instalava dôr em pontada que, num crescendo sem remissão, atingia dentro em pouco aos paroxismos de colica violenta, 
com irradiações para o epigastro, regióes lombar e retro-esternal. Esta crise permaneceu pelo espaço de 10 horas, com periodos curtos de acalmia entrecortados por ezacerbações prolongadas, vomitando tudo quanto ingeria. Melhorou com medicação cujo nome ignora. No dia seguinte teve quatro ou cinco dejeções semi-liquidas, de côr amarelada, sem restos alimentares.

Cinco mezes depois sobreveio nova cólica, com as mesmas caracteristicas da anterior, atribuindo-a á carne de porco que comera na vespera. Passaram-se sete mezes e é então acometida por nova crise, identica ás precedentes, o que a fez procurar o serviço do Dr. Levy Sodré, na Santa Casa.

Todas as cólicas eram sempre seguidas de evacuações diarreicas. Néga ictericia em todo o seu passado mórbido.

O exame do abdome, nesta doente, revela dôr no ponto pancreatocoledociano, e á manobra do psoas. Bordo inferior do figado não palpavel, e o superior no quinto intercosto. Transvero palpavel ao nivel da cicatriz umbelical, não dołoroso. Grande curvatura do estômago palpavel, indolôr. Sigmoide indolôr; cécum não palpavel.

$\mathrm{O}$ exame funcional do aparelho digestivo, feito dois dias depois da scólica, revelou processo fermentatico exageradamente grande, pois a taxa de ácidos organicos totais ascendeu á cifra de 35,6.

A intubação duodenal mostrou coloração e volumes normais para às três biles e ausencia de elementos patológicos.

Uma colecistografia feita pelo Dr. Moretzconh DE CAstro, em 13-2-42, acusa "vesicula aumentada de volume, de contornos regulares, apresentando leve diminuição do poder de concentração, não se observando, porém, sombras calculosas positivas, nem imagens negativas de cálculos. Esvasiamento precoce, total, da vesicula.

Este caso nos parece do tipo hipermovel não só pela diarréia fermentativa, consecutiva ás colicas, como tambem pelo fato da bile B se apresentar normalmente côrada.

\section{DISCINESIAS HIPERTONICAS}

Os sintomas desta variedade superpõem-se aos da colica por litiase; como satélites enumeram-se desde os banaes fenomenos dispépticos constituidos por nauzeas, vomitos, peso post-prandial etc. até ás ictericias com descoloração das fézes.

\section{DIAGNOSTICO}

Como já o afirmamos alhures, as discinésias genuinas são raras; WESTPHAL avalia sua frequencia em cerca de 5 a $10 \%$ entre todas as afecções das vias biliares; é uma cifra talvez demasiado otimista.

Segundo EPPINGER é muito dificil, na pratica, estabelecer-se com rigôr o diagnostico diferencial entre discinésias e as afecções inflamatorias ou a colelitiase; pelo que só a exclusão dơs processos inflamatorios, litiasicos ou neoplasicos, depois de esgotados todos os recursos exploratorios, é que nos autoriza a firmar seu diagnostico. Desta opinião, como tambem já frizamos, compartilha o Prof. VAN DER REIS. 
Ao lado do passado morbido e da exploração semeiologica, em que se, devem levar em grande conta os estigmas neuro-vegetativos, grande valôr subsidiario dão as comprovações radiologicas e a prova de Meltzer-Lyon.

A bile negra, hiperconcentrada, tanto é privativa das vesiculas atonicas como das hipertonicas, afastando-se, é claro, a hipotese de - uma vesicula estatica por aderencias.

Uma ausencia persistente de bile $\mathrm{B}$, com bile A fracamente corada em amarélo, pode ser causada por um espasmo do esfincter de ODdr. Nesses casos a repetição da prova, como o aconselha CHIRAy, pode levar a um resultado positivo.

Um volume de bile B ultrapassando de duas ou tres vezes a sua quantidade-normal pode ser encontrada tanto nas discinésias atonicas como nas do tipo hipercinético. A ausencia de elementos anormaes em bile de paciente com sintomațologia centralizada no hipocondrio direito, tambem constitue, quando associada a outros dados, meio excelente de confecção diagnostica.

VION Bergman, que na intubação se utiliza da pituitrina para eccitar a excreção, adóta o seguinte critério: o esvasiamento muito rapido de bile vesicular abundante, muito espessa, é sintomatica de hipertonia; um escoamento demorado de bile B escassa fala em favồ de atonia.

A colecistografia é de valôr inestimavel. Os conhecimentos basicos para uma interpretação radiologica da, vesicula, segundo FeLDMAN e MORRISON, citados por LIPSCHUTt, são os seguintes: "15 a 20 minutos depois da refeição de prova começam as contrações vesiculares, atingindo seu maximo em 30 minutos. As contrações, ordinariamente, são muito acentuadas, notando-se redução volumétrica do orgão, traduzivel por ưma sombra inferior á metade, podendo mesmo atingir a um terço, da viscera em repouso. Em condições anormaes, porêm, as contrações são pouco acentuadas, podendo mesmo faltar por completo. Praticamente a vesicula que não sę contráe, de maneira suficiente, dentro dos primeiros trinta minutos, raramente poderá faze-lo depois desse tempo; isto é, a vesicula que evacúa a metade ou dois terços de seu conteúdo, dentro dos primeiros trinta minutos, é considerada normal. Uma retenção de mais de $50 \%$, neste periodo, fala por uma discinésia atonica ou hipertonica, dependendo o diagnostico diferencial do aspéto da vesicula"

De acôrdo com CHIRAy as caracteristicas diferenciaes são: "a forma da vesicula atonica modifica-se nas mudanças de posição; geralmente são longas no decubito ventral e parecem, ao contrario, curtas com um fundo largo, na posição erecta. O fundo pode mesmo aparecer em situação horizontal e achatado quando a vesicula toma ponto de apoio sobre o colon. Em taes casos a parte inferior da vesicula mostra-se mais opaca que a região superior, apenas visivel. Isto se deve ao fáto da bile acumular-se na região fundica, sob o influxo da gravidade, não compensada pela elasticidade das paredes vesiculares" 
Nestas posições eréctas "a parte inferior das vesiculas atonicas desce até ao nivel da crista iliaca, ou mais para baixo, ao passo que no decubito dorsal a forma e a situação modificam-se consideravelmente uma vez que o orgão, ganha a parte superior e externa do hipocondrio, ocultando-se sob o bordo inferior do figado".

Entretanto uma vesicula póde oferecer o aspéto de distenção, ou de atonia, e responder normalmente á prova de BOYDEN; nestas cor.dições, opina LIPSCHUTZ, ha realmente atonia da parede vesicular mas não associada a espasmo do esfincter de ODdr.

As vesiculas hipertonicas tendem para a forma esferica, sendo esta muito pouco influenciavel pela atitude erecta ou resupina. Sob a excitação alimentar, - não pela palpação - a vesicula hipertonica se contráe, assume uma forma cilindrica, evacúa parte de seu conteúdo, e volta á forma primitiva mas com volume diminuido"

Um esvaziamento completo, ou quasi, dentro da primeira meia hora, depois da refeição, indica hipercinésia por hipermotilidade.

Outro procésso radiologico que tem enriquecido o capitulo das discinesias, no campo da fisio-patologia, é o da colangiografia opera-. tória. Pablo Mirizzi, entusiasta do método, realiza-a injetando 3 a 5 cms. cubicos de lipiodol, no colédoco, á razão de $1 \mathrm{~cm}$. por minuto. Sob este contrôle a intervenção se realiza nas melhores condições.

\section{TRATAMENTO}

Ha casos em que a situação se resolve cirurgicamente pela secção do esfincter de ODDI, ou pela anastomose do colédoco ao duodeno. (Colédoco-duodenostomose), ou da vesicula ao duodeno (Colecisto-duodenostomose).

A solução, todavia, é quasi sempre de ordem médica. A questão relativa á alimentação será resolvida em cada caso particular, tendo-se em vista as condiçôes personalissimas do paciente; isto é verdade, sobretudo, nos casos de alergia alimentar, onde a prudencia deve ser vigilante na confecção do regime.

Entretanto ha regras geraes que podem servir de padrão: redução nas gorduras, e abstenção de condimentos, conservas, iguarias, alcool. Permitir pequenas quantidades de gordura sob a forma de manteiga fresca, creme de leite ou gemas, desde que não haja inłtolerancia é obvio.

Entre os medicamentos os antiespasmodicos encontram plena indicação, ocupando primeira plana a atropina e seus derivados. A hiperacidez será combatida pelos alcalis, uma vez que póde atuar como fatôr predisponente na hipermotilidade das vias biliares. Outra medicação sugerida para o relaxamento do esfincter, e' cuja eficácia se demonstrou nas experiencias já citadas de BEst e Hicken, é a trinitrina. 
A constipação, si presente, deverá ser eliminada, assim como dever-se-á drenar; constantemente, a vesicula pela administração de saes: biliares ou pela sondagem duodenal. (Lipshutz).

\section{BIBLIOGRAFIA}

Alvarez - An Introduction to Gastro-enterology.

Chiray-Pavel-Lomon - La Vesicule Biliaire et ses voies d'excretion.

EPPINGER - Enfermedades del Higado.

LEPEH Ne - Afecções do Figado e das Vias Biliares.

LIPSCHUTZ - The Review of Gastro-enterology - Vol. 5 - 1938.

Mirizzi - Fisio-patologia del Epato-coledoco - Colangiografia operatoria.

Mirizzi - Surgery, Gynecology and Obstetric - Fevereiro de 1942.

Pavei-Paúnesco-Podeano - Affections non ulcereuses du Duodenum.

Von Bergman - Patologia Funcional.

\section{Gengivas doentes?}

\section{“P Y O R R O N"}

Dá saúde ás gengivas, porque é remédio e... é dentifricio

O departamento de

ADMINISTRAĢ̃̃o PREDIAL

DA

Caixa Geral de Emprestimos

REGULARIZARÁ E AUGMENTARÄ O RENDIMENTO DOS PREDIOS DE V S.

IDONEIDADE ABSOLUTA

PRESTAÇÃO RIGOROSA DE CONTAS

CAIXA GERAL DE EMPRESTIMOS

Caisse Générale de Prêts Fonciers et Industriels

Rua Tabatinguera, 164 - Fone 2-4722 - SÃO PAULO 


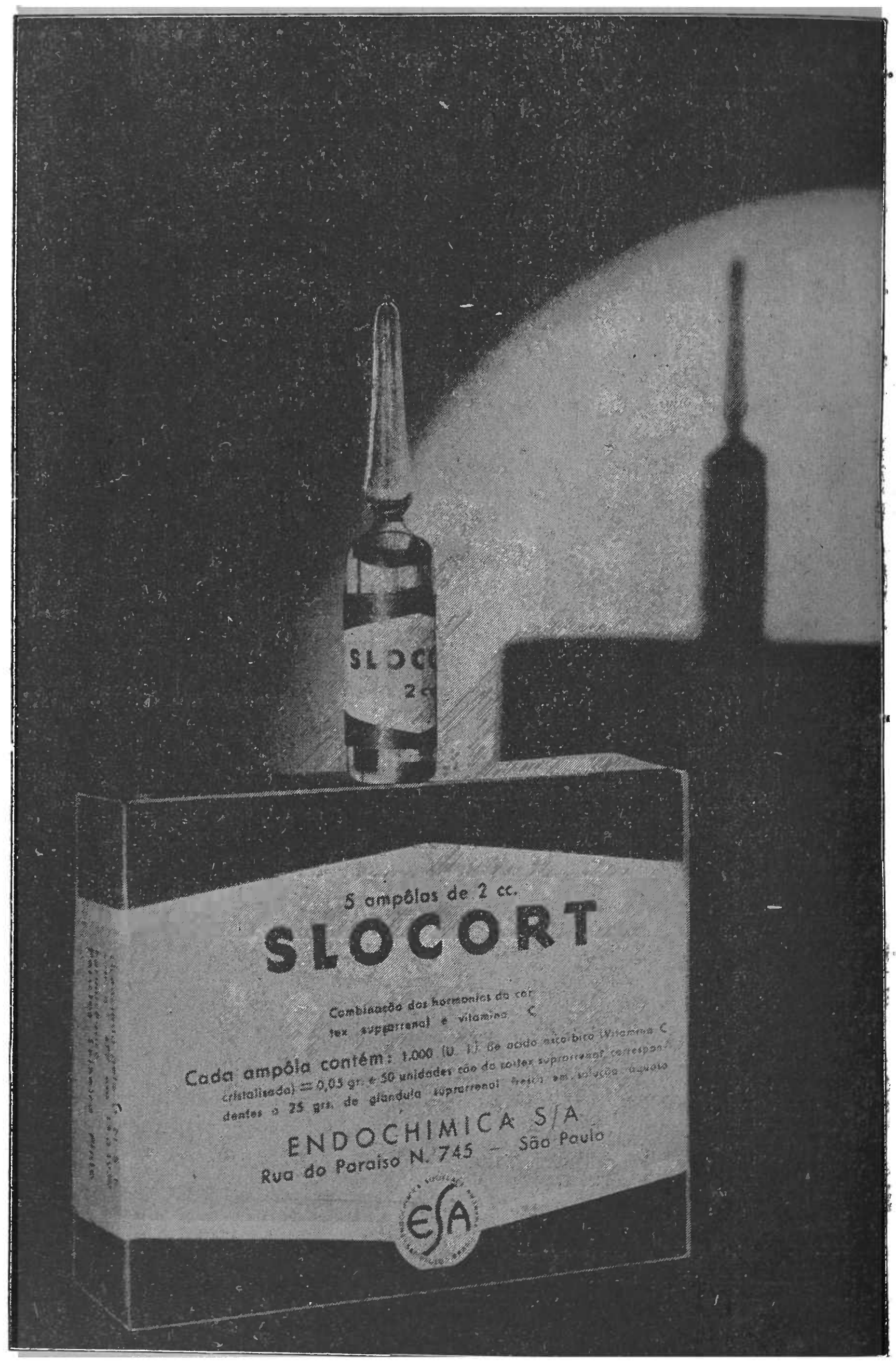

